Arq. Bras. Med. Vet. Zootec., v.65, n.3, p.645-648, 2013

\title{
Granuloma leproide canino na região amazônica - relato de caso
}

\author{
[Canine leproide granuloma in the amazon region - case report] \\ M.B. Almeida ${ }^{1}$, A.P.S. Priebe ${ }^{2}$, J.I. Fernandes ${ }^{1}$, E.M. Yamasaki ${ }^{3}$, T.N. França ${ }^{4}$ \\ ${ }^{1}$ Aluno de pós-graduação - Universidade Federal do Pará Castanhal, PA \\ ${ }^{2}$ Médica veterinária autônoma \\ ${ }^{3}$ Aluna de pós-graduação - Universidade Federal Rural do Rio de Janeiro - UFRRJ - Rio de Janeiro, RJ \\ ${ }^{4}$ Instituto de Veterinária - Universidade Federal Rural do Rio de Janeiro - UFRRJ - Rio de Janeiro, RJ
}

\begin{abstract}
RESUMO
Descreve-se o primeiro caso de granuloma leproide canino na região amazônica, Brasil, em um canino da raça Boxer, procedente do município de Castanhal, Pará, que apresentava lesões nodulares, alopécicas, firmes, ulceradas e não pruriginosas nas duas pinas. Os nódulos foram retirados cirurgicamente e enviados para análise histopatológica. $\mathrm{O}$ exame microscópico revelou marcada infiltração inflamatória constituída por macrófagos, plasmócitos, neutrófilos, linfócitos e células gigantes. A técnica de ZiehlNeelsen evidenciou grande quantidade de bacilos álcool-ácido resistentes no interior de macrófagos e de células gigantes. Houve forte reatividade ao exame imuno-histoquímico para Mycobacterium spp.
\end{abstract}

Palavras-chave: granuloma leproide, região amazônica, patologia

\begin{abstract}
This study describes the first case of canine leproid granuloma in the Amazon region, Brazil. A Boxer dog from the city of Castanhal, Pará presented nodular, alopecic, firm, ulcerated, non-pruritic lesions on both pinnae. The nodules were removed surgically and submitted to histopathological analysis. The microscopic exam revealed marked inflammatory infiltrate composed of macrophages, plasma cells, neutrophils, lymphocytes and giant cells. The Ziehl-Neelsen staining technique showed a large amount of alcohol-acid resistant bacilli inside macrophages and giant cells. The samples exhibited a strong immunohistochemical reaction to Mycobacterium spp.
\end{abstract}

Keywords: leproide granuloma, Amazon Region, pathology

\section{INTRODUÇÃO}

O granuloma leproide canino (GLC) é causado por uma espécie nova de micobactéria que ainda não foi tipificada, a qual, filogeneticamente, relaciona-se com Mycobacterium tilburgii, $M$. simiae e M. genavense (Hughes et al., 2000; Foley et al., 2002) e, no Brasil, pela espécie $M$. murphy (Conceição et al., 2011).

Análise por PCR e sequenciamento genético do DNA demonstraram não haver variabilidade e sim homologia entre 99 e 100\% das bactérias estudadas na Austrália, Nova Zelândia e Estados Unidos (Hughes et al., 2000; Foley et al., 2002).
O organismo é provavelmente saprófita, e, até o momento, tentativas de cultivo têm fracassado (Malik et al., 1998; Hughes et al., 2000; Foley et al., 2002).

A doença acomete cães de um a 11 anos, com média de 5,8 anos. Os caninos da raça Boxer parecem ser os mais afetados (Larsson e Maruyama, 2007; Conceição et al., 2011). Clinicamente, as lesões se caracterizam por nódulos alopécicos, ulcerados, que envolvem derme e subcutâneo e aparecem na porção dorsal da pina, na face e nos membros anteriores, podendo ocorrer uni ou bilateralmente (Foley et al., 2002).

Recebido em 2 de março de 2012

Aceito em 6 de março de 2013

E-mail: begeres@yahoo.com.br 
O diagnóstico pode ser realizado por biópsia e histopatologia. Os cortes histológicos demonstram dermatite nodular a difusa, paniculite, ou ambas, caracterizadas por infiltração difusa de macrófagos, neutrófilos e alguns linfócitos ou plasmócitos na derme e no panículo (Scott et al., 1996; Foley et al., 2002). O processo inflamatório pode ganhar a forma de granulomas ou piogranulomas compactos a coalescentes (Conceição et al., 2011). Pela coloração pelo Ziehl-Neelsen, podem-se observar bacilos álcool-ácido resistentes, em número variável, no interior dos macrófagos ou no centro dos granulomas (Foley et al., 2002). Técnicas de imuno-histoquímica para as diferentes espécies de Mycobacterium podem ser realizadas visando identificar $\mathrm{o}$ agente. A identificação do agente também pode ser realizada por meio de PCR de material coletado das lesões (Conceição et al., 2011).

Casos de GLC foram documentados no Brasil, em São Paulo (Larsson et al., 1994). O presente trabalho tem como objetivo relatar a ocorrência de granuloma leproide em um canino na região amazônica.

\section{CASUÍSTICA}

Um canino da raça Boxer, macho, com seis anos de idade e pesando $28 \mathrm{~kg}$, foi atendido em uma clínica veterinária do município de Castanhal/PA. O proprietário informou que o animal apresentava dois nódulos de crescimento rápido nas pinas. Ao exame clínico, constataramse dois nódulos de tamanhos semelhantes, medindo $3 \mathrm{~cm} \times 2 \mathrm{~cm} \times 2 \mathrm{~cm}$, alopécicos, firmes, ulcerados, não pruriginosos, na região dorsal das pinas (Fig. 1).

A suspeita clínica inicial foi de neoplasia, optando-se pela realização de conchectomia bilateral com margem cirúrgica. $\mathrm{O}$ material retirado cirurgicamente foi fixado em formalina tamponada a $10 \%$ e enviado ao Laboratório de Patologia Animal da Universidade Federal do Pará, onde foi incluído em parafina, cortado a
$5 \mu \mathrm{m}$ de espessura e corado pelas técnicas de hematoxilina e eosina e Ziehl Neelsen para realização de exame histopatológico. $\mathrm{O}$ exame histopatológico dos nódulos revelou marcada infiltração inflamatória difusa por macrófagos, plasmócitos, neutrófilos e ocasionais linfócitos na derme e ao redor das glândulas anexas. Células gigantes e macrófagos epitelioides com citoplasma espumoso também estavam presentes (Fig. 2), assim como granulomas parcialmente delimitados por finos septos de tecido conjuntivo fibroso. Na epiderme, neutrófilos , sobretudo, próximos às áreas de ulceração, também foram envidenciados. A coloração pelo Ziehl-Neelsen revelou bacilos álcool-ácido resistentes no interior de macrófagos e células gigantes (Fig. 3).

Para a realização da técnica de imunohistoquímica, os fragmentos foram desparafinados em xilol e hidratados em álcool. A peroxidase endógena tecidual foi inativada com $\mathrm{H}_{2} \mathrm{O}_{2}$ a $3 \%$ em solução aquosa por 30 minutos; em seguida, as lâminas foram lavadas com água destilada. No intuito de inibir as reações inespecíficas, os fragmentos foram submetidos a tratamento com leite em pó desnatado (Molico®) a $5 \%$ em solução aquosa por 30 minutos e lavados novamente em água destilada. Em seguida, as lâminas foram incubadas overnight a $6^{\circ} \mathrm{C}$ (em geladeira) com anticorpo policlonal primário contra Mycobacterium tuberculosis (GeneTex, cat\#20905) diluído a 1:1000 em PBS. Após o período de incubação, as lâminas foram lavadas em água destilada. Para revelar a reação, utilizou-se o método do complexo avidina-biotina peroxidase (kit comercial LSAB Dako, cat\#0690) e cromógeno DAB, 3,3'diaminobenzidina (Dako, Cat\# K3468), de acordo com as instruções do fabricante. As lâminas foram contracoradas com hematoxilina de Harris e, em seguida, desidratadas, diafanizadas e montadas com goma damar diluída em xilol. A avaliação das lâminas sob microscopia ótica demonstrou a positividade para Mycobacterium spp. (Fig. 4). 


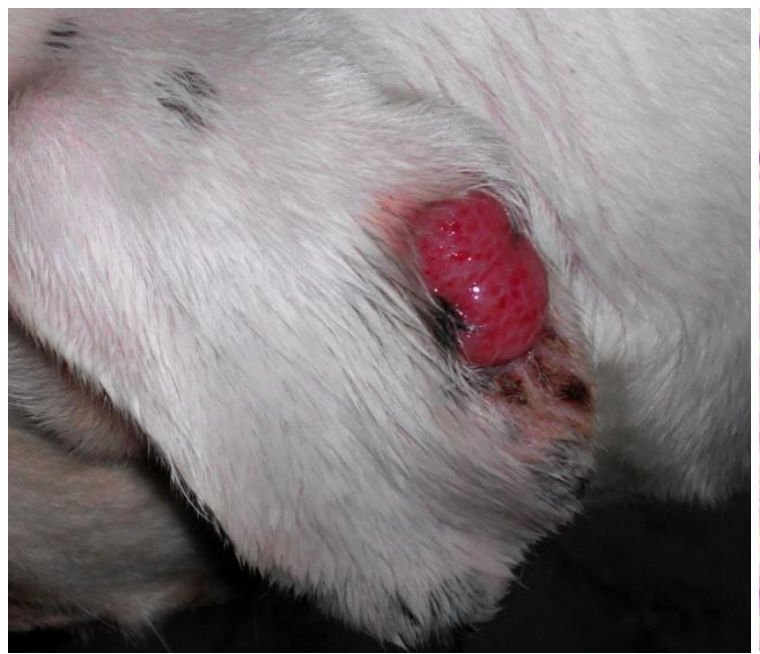

Figura 1. Cão. Granuloma leproide canino. Lesão nodular, ulcerativa, medindo $3 \mathrm{~cm} \times 2 \mathrm{~cm} \times 2 \mathrm{~cm}$ na região dorsal da pina esquerda.

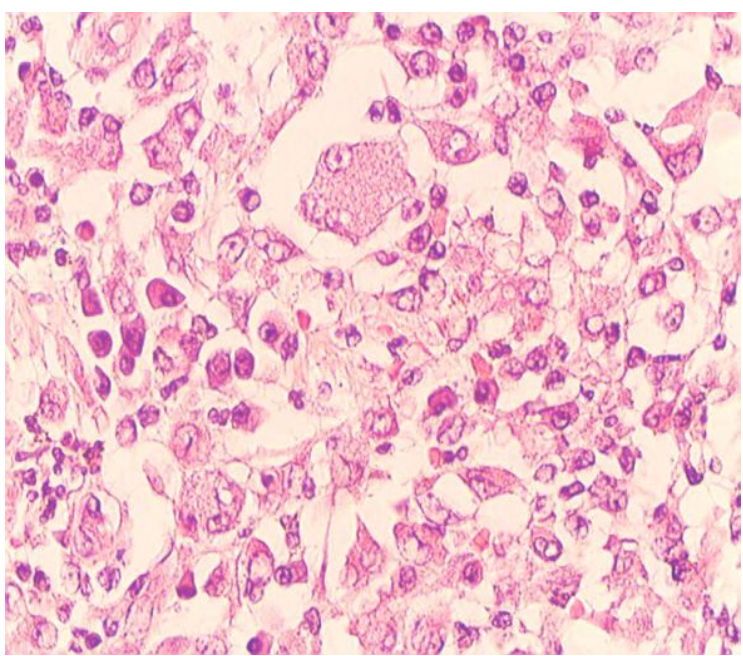

Figura 2. Cão. Granuloma leproide. Infiltração por macrófagos, plasmócitos, alguns neutrófilos e células gigantes na derme. HE 40x.

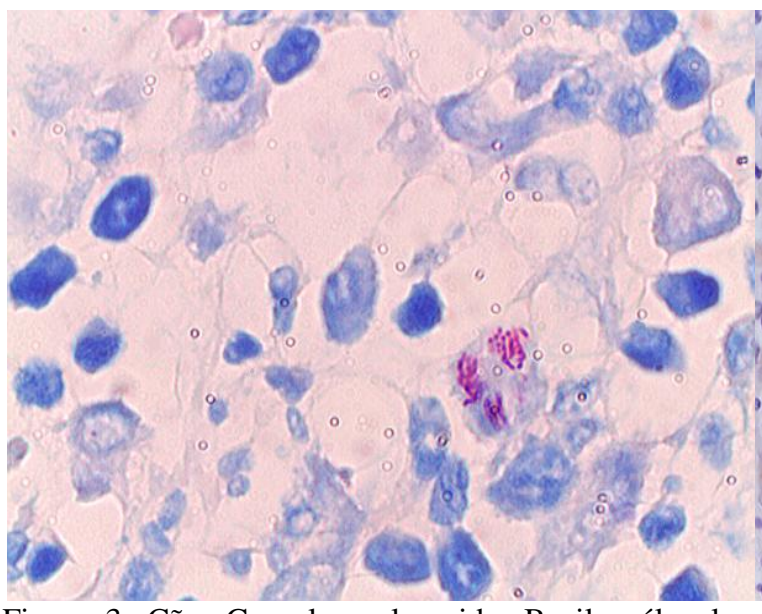

Figura 3. Cão. Granuloma leproide. Bacilos álcoolácido resistentes no interior de um macrófago. ZN 40x.

\section{DISCUSSÃO}

Embora não se conheça completamente a etiopatogenia do GLC, suspeita-se que insetos, como mosquitos, sejam responsáveis pela inoculação do agente (Malik et al., 1998). Solo contaminado, traumatismos, inoculação durante brigas, material cirúrgico ou agulhas contaminadas são as principais formas de transmissão (Silva et al., 2010). A interferência dos felinos na patogenia da doença também é proposta por alguns autores (Scott et al., 1996; Foley et al., 2002). Neste caso, não havia, na história clínica do paciente, qualquer contato dele com felinos ou problemas relacionados a

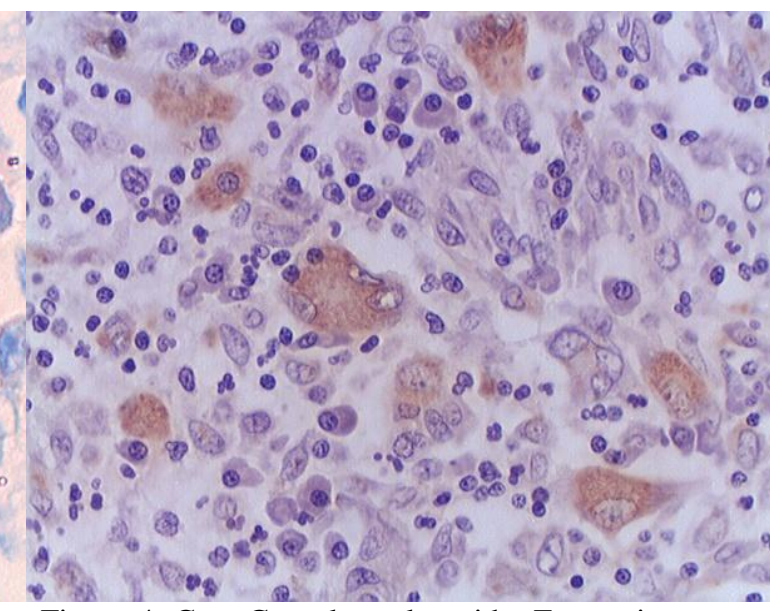

Figura 4. Cão. Granuloma leproide. Exame imunohistoquímico positivo para Mycobacterium spp. IHQ 40x.

mosquitos, embora existam, na região, diversas espécies que repastam em cães.

Clinicamente, o GLC acomete com maior frequência animais de pelo curto, e aparentemente a raça Boxer está especialmente predisposta a desenvolver a patologia (Matousek, 2004; Conceição et al., 2011). Contudo, outras enfermidades que cursam com aumento de volume local também têm a raça Boxer como uma das raças mais predispostas, dificultando o diagnóstico, especialmente em regiões onde não há casos de GLC documentados. 
A ressecção cirúrgica das lesões é um tratamento eficiente, embora possa ocorrer cura espontânea em seis meses; o prognóstico é excelente mesmo sem tratamento (Foley et al., 2002). A cirurgia realizada no paciente promoveu a cura, entretanto sabe-se que o uso de antibióticos pode ser uma boa alternativa (Malik et al., 2001).

O diagnóstico de GLC pode ser realizado por meio de histopatologia e coloração pela técnica de Ziehl-Neelsen, que demonstra bacilos álcoolácido resistentes no interior de macrófagos ou no centro dos granulomas (Scott et al., 1996). No presente caso, o diagnóstico foi firmado pela coloração pelo Ziehl Neelsen em cortes histológicos e pelo exame imuno-histoquímico, que identificaram a presença de Mycobacterium spp. nas lesões.

Os diagnósticos diferenciais para GLC incluem lesões nodulares (neoplásicas ou não) que ocorrem com frequência na face e na cabeça, como tumores de células basais (tricoblastoma) (Vail e Withrow, 2007), histiocitoma cutâneo canino, plasmocitoma cutâneo, mastocitoma, bem como granuloma estéril idiopático (Hargis e Ginn, 2009) e micoses subcutâneas (Scott et al., 1996). As avaliações citológica e histopatológica das lesões geralmente estabelecem o diagnóstico correto, evitando equívocos terapêuticos.

Conclui-se que o GLC deve ser considerado como importante diagnóstico diferencial das lesões nodulares que afetam cães na região Norte do Brasil.

\section{REFERÊNCIAS}

CONCEIÇÃO, LG.; ACHA, LM.; BORGES, AS. et al. Epidemiology, clinical signs, histopathology and molecular characterization of canine leproid granuloma: a retrospective study of cases from Brazil. Vet. Dermatol., v.22, p.249256, 2011.

FOLEY, J.E.; BORJESSON, D.; GROSS, T.L. et al. Clinical, microscopic and molecular aspects of canine leproid granuloma in the United States. Vet. Pathol., v.39, p.234-239, 2002.
HARGIS, A.M.; GINN, P.E. O Tegumento. In: McGAVIN, M.D.; ZACHARY, J.F. Bases da Patologia em Veterinária. Brasil: ELSEVIER, 2009. p.1252-1253.

HUGHES, M.S.; JAMES, G.; BALL, N. et al. Identification by $16 \mathrm{~S}$ rRNA Gene Analysesof a Potencial Novel Mycobacterial Species as an Etiologycal Agent of Canine Leproid Granuloma Syndrome. J. Clin. Mycrob., v.38, p.953-959, 2000.

LARSSON, C.E.; MARUYAMA, S. Micobacterioses. Rev. Clin. Vet., v.72, p.36-44, 2007.

LARSSON, C.E.; MICHALANY, N.S.; PINHEIRO, S.R. et al. Mycobacteriosis in domestical dogs - Report of two cases. Rev. Fac. Med. Vet. Zootec. USP, v.31, p.35-41, 1994.

MALIK, R.; LOVE, D.N.; WIGNEY, D.I. et al. Mycobacterial nodular granulomas affecting the subcutis and skin of dogs (canine leproid granuloma syndrome). Aust. Vet. J., v.76, p.403407, 1998.

MALIK, R.; MARTIN, P.; WIGNEY, D. et al. Treatment of canine leproid granuloma syndrome: preliminary findings in seven dogs. Aust. Vet. J., v.79, p.30-36, 2001.

MATOUSEK, J.L. Diseases of the ear pinna. Vet. Clin. Small Anim., v.34, p.511-540, 2004.

SCOTT, D.W.; MILLER D.H.; GRIFFIN C.E. Doenças fúngicas da pele. In: Muller \& Kirk's Dermatologia de pequenos animais. Rio de Janeiro: Interlivros, 1996. p.289-359.

SILVA, D.A.; GREMIÃO, I.D.F.; MENEZES, R.C. et al. Micobacteriose cutânea atípica felina autóctone no município do Rio de Janeiro-Brasil. Acta Sci. Vet., v.38, p.327-331, 2010.

VAIL, D.M.; WITHROW, S.J. Tumors of the Skin and Subcutaneous Tissues. In: WITHROW, S.J.; VAIL, D.M. (4.ed). Small Animal Clinical Oncology. Canada: SAUNDERS, 2007, p.385. 